\title{
INDETERMINAÇÃO, MULTIDIMENSIONALIDADE E RELEVÂNCIA DO PROCESSO DE CONSTRUÇÃO DE SIGNIFICADOS ${ }^{1}$
}

\author{
Mônica F. B. Correia*
}

\begin{abstract}
RESUMO. Expressões frequentemente utilizadas em nossos discursos, como “internalização", "intersubjetividade” e objeto deste estudo - "processo de construção de significados", embora discutidas e presentes há décadas, não são bem definidas como parecem. Em face disso, nosso principal objetivo foi propor uma composição para o PCS a partir de análises realizadas por diferentes autores e áreas. As discussões, neste sentido, postulam o envolvimento de três componentes, mais a coparticipação da linguagem, e de diferentes dimensões para este processo, além de evidenciarem a importância do tema para a investigação da mente e da constituição social desta. A cognição relaciona-se a todos os fenômenos vinculados à produção do conhecimento, colocando o PCS - inerente a este - como objeto de estudo da Psicologia. Esta capacidade de empregar funcionalmente os signos, a qual nos diferencia de outros animais, no entanto, tem sido pouco compreendida pela Psicologia.

Palavras-chave: Processo de construção de significados; significação; cognição.
\end{abstract}

\section{INDETERMINATION, MULTIDIMENSIONALITY AND RELEVANCE OF THE PROCESS OF MEANING CONSTRUCTION}

\begin{abstract}
Frequently used expressions which are part of our speeches, such as 'internalization', 'intersubjectivity' and, the one which is object of study, 'process of meaning construction', even though being discussed and being present for decades, are not so well defined as it may seem. Our main objective was, therefore, to propose a composition to the PMC from the analysis carried out by different authors and areas. The discussions, in this sense, postulate the involvement of three components and also the co-participation of the language, and of different dimensions to this process; and also show the importance of the theme to the investigation of the mind and its social constitution. The cognition is related to all phenomena linked to the knowledge production, putting the PMC - inherent to this - as object of study of Psychology. This ability to apply the signs functionally, what differs us from other animals, however, has not been fully understood by Psychology.
\end{abstract}

Key words: Process of meaning construction; meaning; cognition.

\section{INDETERMINACIÓN, MULTIDIMENSIONALIDAD Y RELEVANCIA DEL PROCESO DE CONSTRUCCIÓN DE SIGNIFICADOS}

\begin{abstract}
RESUMEN. Expresiones frecuentemente utilizadas en nuestros discursos, como "internalización”, "intersubjetividad" y - objeto de este estudio - "proceso de construcción de significados", mismo discutidas y presentes hace décadas, no son bien definidas como parecen. Por eso, nuestro principal objetivo fue proponer una composición para el PCS a partir de análisis realizados por diferentes autores y áreas. Las discusiones, en este sentido, postulan el envolvimiento de tres componentes, pero la coparticipación del lenguaje, y de diferentes dimensiones para este proceso, además de evidenciaren la mportancia del tema para la investigación de la mente y de la constitución social de esta. La cognición se relaciona a todos los fenómenos vinculados a la producción del conocimiento, colocando el PCS - inerente a este - como objeto de estudio de la Psicología. Esta capacidad de emplear funcionalmente los signos, la cual nos diferencia de otros animales, entre tanto, ha sido poco comprendida por la Psicología.
\end{abstract}

Palabras-clave: Proceso de construcción de significados; significación; cognición.

\footnotetext{
Texto derivado de reflexões baseadas na tese de doutorado da autora.

Apoio: CAPES

* Doutora em Psicologia, professora da Universidade Federal Paraíba.
} 
Existem expressões tão comumente utilizadas em nossos discursos que parecem bem definidas e operacionalizadas ou gozar de algum consenso, mas isto não se aplica a vários dos conceitos frequentemente utilizados em cenários psicológicos e pedagógicos, a exemplo de "internalização", "intersubjetividade" e mesmo do fenômeno aqui em análise, o processo de construção de significados (PCS) ou significação. As discussões em torno da capacidade humana de construir significados e da importância desta para o funcionamento cognitivo, no entanto, remontam a muitas décadas. Antes mesmo da chamada revolução cognitiva (meados dos anos 50) já se enfatizava a relevância do significado na configuração dos fenômenos psicológicos, de maneira que muitos autores concordavam que significado representa o principal aspecto da cognição humana e o problema-chave da Psicologia Cognitiva (Correia, 2003). Neste sentido, tal indefinição envolve, inclusive, conceitos cuja importância para o desenvolvimento da cognição humana é amplamente reconhecida.

A abordagem desse reconhecimento em torno do processo de construção de significados envolve diferentes ciências. Na filosofia da linguagem, por exemplo, Frege, tentando demonstrar a importância do significado, chamava a atenção para o fato de que em nossas interações construímos e compartilhamos coisas que vão além do formato aparente (Costa, 2003). Em outro cenário, Vygotsky afirmava que a mente resulta de internalizações, mediadas pelos instrumentos materiais e simbólicos, que ocorrem desde os primeiros dias de vida da criança. Esta mediação é possível graças às relações interpessoais em que o individuo se vê envolvido e que permitem a significação dos seus atos. Bakhtin, por sua vez, considera os signos "alimento da consciência individual, a matéria de seu desenvolvimento", destacando ainda o fato de que os animais, apesar de nascerem fisicamente da mesma forma que os humanos, não entram na história. (Freitas, 1998; p. 93) O ser humano para isto precisa de um segundo nascimento: o social. A consciência adquire, assim, forma e existência nos signos criados por um grupo organizado no curso de suas relações sociais (Freitas, 2002). Neste sentido, a cognição deve ser entendida como ação significativa no mundo e a comunicação como um processo social e coletivo de produção online (aqui e agora) de significados em coautoria (dialogismo).

As análises de estudos realizados há décadas, ou neste momento histórico, assinalam, além da importância, a necessidade de se tomar o PCS como objeto de estudo, buscando-se avançar em investigações relacionadas às funções mentais superiores e aos processos específicos que as constituem. A importância do PCS para a constituição da mente, dessa maneira, vem sendo abordada por inúmeros estudiosos (Wittgesntein, citado por Condé, 1998 e por Chauviré, 1991; Frege, citado por Costa, 2003; Marková, 1990; Piaget, 1990; Vygotsky, 2001; Bakhtin, 2002) e apontada como objeto de estudo da Psicologia. Essa discussão, portanto, está presente na Psicologia, e sob diferentes óticas, embora especialmente entre autores cujas filiações teóricas aproximam-se das chamadas correntes sociointeracionistas ou culturalistas. Não obstante, as tentativas de demonstrar as dimensões e a importância deste processo ultrapassam, como referido, o cenário da Psicologia, e este problema tem assumido várias "vozes", a exemplo também da linguística cognitiva, constituindo-se como um problema multidisciplinar. Para abordar o PCS, então, é preciso inserir-se em diferentes áreas - psicologia, linguística, filosofia e biologia - no sentido de tentar mapear o processo.

O objetivo deste estudo, nesse sentido, é construir uma composição, ao menos preliminar, do PCS, partindo das análises realizadas por diferentes autores e áreas que abordam o tema, e além disso, apresentar hipóteses sobre sua gênese e discutir a viabilidade de investigá-lo empiricamente. Espera-se, dessa forma, contribuir para o esclarecimento de um fenômeno que, apesar de discutido e colocado como eixo da cognição, permanece pouco compreendido.

\section{COMPONENTES DO PROCESSO DE CONSTRUÇÃO DE SIGNIFICADOS}

Juntamente com o reconhecimento da complexidade e importância da construção de significados para a cognição encontram-se algumas lacunas a respeito da composição e funcionamento deste processo. Para analisar esta composição tomaram-se por base autores cujos estudos direta ou indiretamente envolvem "construção de significados". Iniciaremos com a indicação de imprevisibilidade deste fenômeno, que de certa maneira busca justificar as dificuldades relacionadas a sua abordagem e compreensão:

A tese da mediação simbólica da vida mental pressupõe uma região de indeterminação, não apenas para o sentido lingüístico, como também para os processos mentais, na medida em que estes também estão na dependência dos diversos processos em jogo 
na significação: ou seja, não são comportamentos previsíveis ou apriorísticos. (Morato, 1996, p. 18; grifos nossos)

Nesta citação vemos proferido o envolvimento de "processos" na significação, tal como enfatiza também Pino (1995) ao falar do universo de signos e dos processos de significação como vias de acesso ao mundo cultural. Não há, no entanto, em nenhum dos casos, pistas sobre como tais processos ocorrem ou como reconhecê-los, do que emerge o problema da indefinição relacionada à constituição do PCS.

Valsiner (2001 \& 2002) argumenta que a irreversibilidade do tempo, fato que se deve contar ao pensar em desenvolvimento cognitivo, é driblada através da construção de significados, pois os signos criam relativa estabilidade dentro do campo de experiência e capturam características de fluxo irreversível de experiência pessoal, permitindo à pessoa transcender o fluxo corrente da experiência aqui e agora. Sendo assim, mediante o uso de signos os seres humanos podem transcender qualquer contexto de atividade e são capazes de antecipar eventos que ocorrem em um futuro imediato, além de utilizar experiências do passado para enfrentar o futuro.

Outros autores, por sua vez, já postulam o envolvimento de certas dimensões ou composições para o PCS. Oliveira (1995), por exemplo, afirma que seria a linguagem a responsável por todo o PCS, uma vez que o signo mediador é considerado o mecanismo gerador de significados; e esse processo, por sua vez, seria responsável pelo desenvolvimento psicológico. Atribuir um papel protagonístico, digamos assim, à linguagem, ou colocar sua importância como fundamental neste processo, é de fato um dos consensos. O problema, porém, segundo Fauconnier (1996), é que o efeito (significado), neste caso, está sendo atribuído essencialmente às causas visíveis (linguagem). Em outras palavras, para esse autor, a linguagem seria a ponta de um "iceberg cognitivo espetacular", observado na comparação entre a brevidade da forma linguística e a riqueza da construção de significados (meaning construction) correspondente, mas não explicaria, por si, o processo. "Nós não temos ciência dessa maravilhosa cadeia de eventos cognitivos que tomam lugar quando nós falamos e escutamos, exceto pela manifestação externa de linguagem (sons, palavras, sentenças) e a manifestação interna de significado: com rápida centelha, nós experenciamos significado". (p. 5)

As discussões sobre a cognição humana do ponto de vista filogenético também tendem a invocar a linguagem como razão da unicidade do processo, no sentido de especificidade humana; mas é preciso recordar da mesma maneira - ainda argumentando contra uma justaposição entre a linguagem e o PCS que a linguagem, parafraseando Tomasello (1999), não se origina no espaço e cai na terra, nem é uma mutação genética (como Chomsky teria afirmado) sem conexão com outros aspectos da cognição humana e da vida social, embora não haja dúvidas sobre sua participação expressiva na natureza da cognição humana.

Então é fato que a habilidade com símbolos linguísticos coloca a criança numa posição para conquistar vantagens de habilidades sociais e de conhecimentos preexistentes na sua comunidade local e a cultura como um todo. Assim, pode-se dizer que a linguagem está imbricada com o PCS, mas não que é o PCS ou que responde a todas as questões vinculadas a este. Maturana (2001) compartilha deste entendimento, pois concorda com a importância da linguagem, mas também sem identificá-la como o PCS, argumentando que o significado "é uma reflexão do observador e não um elemento na linguagem ou no funcionamento da linguagem.” (p. 88) Há uma afirmação conveniente a esta discussão, porque reforça o argumento de que a linguagem constitui parte fundamental na construção de significados, mas não a descreve: a linguagem não é transparente e significa inclusive por meio do "não dito", é polissêmica. (Smolka, 1995) Além disso, muitas vezes gera equívocos, ilusões e mal-entendidos.

Pode-se afirmar, nesse sentido, que existe concordância sobre a participação fundametal da linguagem na cognição humana, sendo inclusive o seu diferencial; entretanto, pode-se afirmar também a sua insuficiência para explicar toda a complexidade do PCS. A linguagem poderia ser compreendida como, dialeticamente, produto e produtora da capacidade humana de construir significados. Dessa maneira, entende-se que o PCS é que faz da linguagem uma atividade, uma construção dinâmica, e ainda que haja um paralelismo, um interjogo, não há uma justaposição entre estes fenômenos. Pode-se abstrair dessas discussões, portanto, que o problema do rastreamento do processo de construção de significados não estaria solucionado pela sua tradução em "linguagem".

É possível encontrar outras especulações nessa direção, ou seja, especulações que compartilham da hipótese do envolvimento, no PCS, de outros componentes, além do fundamental papel da linguagem. Pode-se imaginar, por exemplo, que os indivíduos criam significados para eles próprios e potencialmente para seus ouvintes ou leitores. A 
comunicação demanda uma espécie de tradução de um tipo de símbolo (pessoal e privado) para outro (cultural e público) (Percy, 1994). Deduz-se ainda que existe a produção de significados para si e o compartilhar de significados, que envolve um 'Outro'. A direção que a construção de significados pode assumir, então, depende da interação com um Outro. Envolve o Outro mesmo depois de ser significado para o próprio indivíduo, pois só será útil se puder ser compartilhado. A construção de significados, dita de outra maneira, existe a partir do Outro e, ao mesmo tempo, para o Outro; colocando em evidência mais um componente para o PCS, além da coparticipação da linguagem: a interação (ou o Outro ${ }^{2}$ ). "A significação pertence a uma palavra enquanto traço de união entre os interlocutores [...] é o efeito da interação do locutor e do receptor [...]". (Bakhtin, citado por Pino, 1995; p. 132)

Dessa maneira nos é lembrado que a palavra é carregada de significação, embora nem sempre consiga traduzir todo o significado, tampouco garantir uma concordância entre interlocutores. Muitas vezes, ao contrário, limita, camufla e até distorce os significados. 'Palavra' significa discurso, pois, de acordo com Bakhtin, corresponde ao grego 'logos', cuja tradução é discurso. Não se pode perder de vista ainda, principalmente nesta discussão, que "o significado das palavras evolui e que não há imutabilidade dos significados das palavras" (Vygotsky citado por Banks-Leite, 1995 p. 51). Neste sentido podemos dizer que, além da linguagem, é possível abstrair outro componente para o PCS: a interação, participação direta ou indireta de um Outro.

Góes (1995) concorda com a participação do Outro e ainda acrescenta: "O conhecer envolve mediação pelo outro [interação] e produção de significados e sentidos em relação a objetos culturalmente configurados [artefatos]" (p. 23). Assim, o PCS deve envolver mais um componente em sua constituição, um objeto, classificando o fenômeno como multidimensional. Esta característica, sugerida também por outros autores, envolveria pelo menos três dimensões: social, cognitiva e de intencionalidade. (Coll \& Edwards, 1998) Para Brait (1997), por seu turno, construção de significados tem vários enfoques nos estudos linguísticos em geral e na produção de estudiosos como Bakhtin, para quem as análises deveriam levar em consideração a história, o tempo particular, o lugar de geração do enunciado e os envolvimentos intersubjetivos que dizem respeito a

2 Outro do dialogismo de Bakhtin: histórico e ideológico; diferentes vozes sociais. um dado discurso, o que também configura diferentes dimensões a serem consideradas.

Entende-se que estas diferentes dimensões, caracterizadas pelos componentes do PCS, atuariam também através de ações orientadas, necessárias para colocar o processo em funcionamento, e requereriam uma atenção dirigida, envolvendo intencionalidade. A produção de significados em direção a um determinado tema necessitará, neste sentido, da anuência do indivíduo. Para manifestar comportamentos sociais a criança precisa estar motivada, além de possuir as habilidades necessárias para o compartilhamento social.

Então, é possível 'capturar', ainda na teoria, a postulação do envolvimento de pelo menos três componentes no PCS, além da coparticipação da linguagem: (1) a Interação - pois há sempre a interação com outro indivíduo, presencial ou não, que instiga e direciona as tentativas de construção de significados; (2) um objeto - pois a possibilidade de construir significados envolve um artefato material, inicia-se a partir de algo para o qual as ações são dirigidas, e este algo invariavelmente está impregnado de significados culturais; e (3) a Atenção dirigida pois para significar é necessário estar voltado para algo ou para algum evento; ter a intenção de significálos. Geralmente, mas não necessariamente, está ligada também à volição. Estes componentes, portanto, são as ênfases para a composição do processo, essencialmente humano, de construção de significados.

Retomando a questão, os componentes em evidência apontam diferentes dimensões para o PCS: uma dimensão cultural, pois necessita de um sistema simbólico e de artefatos que possuam um significado compartilhado ou que possa ser compartilhado; uma dimensão interacional, uma vez que necessita do Outro para mediar tais significados; e uma dimensão individual, porque a ação precisa ser dirigida e, geralmente, ser voluntária. Tomasello (1999), ao falar da "cultura humana" também fala do envolvimento de dimensões, afirmando que a cultura humana é um produto evolucionário recente e que a cognição é um produto de eventos genéticos, culturais e pessoais, portanto, dimensões evolucionárias, históricas e ontogenéticas, respectivamente. Relacionado a esta característica de multidimensionalidade do processo de construção de significados pode-se trazer ainda, sem pretender ser exaustivo, o comentário de Bronckart (1999) a respeito do objetivo de Vygotsky de construir um conceito que pudesse agregar as diferentes dimensões (para este autor biofisiológicas, comportamentais, mentais, sociais e verbais) que 
caracterizam as condutas humanas e que deveria ser lembrado ao se pensar na unidade de análise mais fundamental da Psicologia. "Esse objetivo, entretanto, não foi atingido no desenvolvimento do seu trabalho, hesita o autor [Vygotsky] entre diversos candidatos a esse estatuto, em particular entre as noções de significação da palavra, conduta instrumental e atividade mediada pelos signos". (Bronckart, 1999; p. 29; grifo nosso). Acredita-se que o conceito que "agrega diferentes dimensões" é a significação, uma das possibilidades levantadas, mas não desenvolvida por Vygotsky.

A característica de multidimensionalidade do PCS pode ser ilustrada ainda por dois outros estudos, agora empíricos (Goodwin, 2000; Meira \& Lerman, 2001), o que demonstra, ao mesmo tempo, a viabilidade da investigação do PCS. As análises de Goodwin (2000), de interações entre garotas jogando "amarelinha" em um momento e de arqueólogos em seu trabalho de escavações em outro, são utilizadas para discutir o envolvimento de diversos meios semióticos e a criação de campos semióticos ${ }^{3}$ nas ações sociais humanas. De acordo com Goodwin, a produção e a interpretação das ações sociais humanas são constituídas através do desenvolvimento simultâneo de diversos destes meios e envolveriam justaposições dinâmicas e temporárias de campos semióticos. Esta proposição revela forte semelhança com a desenvolvida anteriormente para a composição do PCS, pois aponta a linguagem e a estrutura material do ambiente como "componentes integrados de um processo comum para a produção social de significado e ação" e declara que procura identificar disposições particulares e situadamente relevantes de campos semióticos que estariam em um processo contínuo de mudança para produção de significados e ação. (p. 1490)

Meira e Lerman (2001), por sua vez, através da discussão de um modelo explicativo da Zona de Desenvolvimento Proximal (ZDP) (Vygostsky, 1991), a partir de uma concepção semiótica, também identificam nas análises de diálogos entre professor e aluno na sala de aula campos semióticos propiciadores de construções de significados.

Por fim, podemos afirmar que as análises realizadas até este momento, teóricas ou empíricas, autorizam-nos a construir algumas proposições sobre o processo em discussão: a) o PCS consiste em elaborar, reelaborar e, por último, ampliar o objeto de significação, e nesse sentido, significar possibilita a

3 Campos semióticos seriam campos que se justapõem para mutuamente se aperfeiçoarem; uns são considerados relevantes (e adicionados) e outros irrelevantes (e abandonados). construção de conhecimento; (b) estes movimentos (elaborar, reelaborar e ampliar o objeto de significação) aparecerão nas ações do indivíduo; (c) o PCS envolve diferentes componentes, todos atuando concomitantemente para possibilitar a produção de significados para a ação; e (d) o PCS é acessível empiricamente.

\section{GÊNESE DO PROCESSO DE CONSTRUÇÃO DE SIGNIFICADOS}

Nas discussões a respeito do PCS sobressaem ainda hipóteses relacionadas a sua origem, se biológica ou cultural. Alguns autores buscam, ao invés do confronto, o equilíbrio entre as hipóteses de origem biológica e cultural. Donald (2000), por exemplo, mostra que a natureza do ambiente cultural tem influente determinação na natureza das habilidades operacionais de uma criança. A cultura, então, forneceria muito mais que detalhes incidentais da vida mental, na verdade estruturaria a mente de maneira tão fundamental que se tornaria parte do mecanismo de replicação evolucionária e da seleção natural. Falando de primatas não-humanos, dos símbolos e do processo de aculturação, essa autora lembra que a capacidade para o pensamento simbólico é apenas vagamente definida no sistema nervoso; o próprio cérebro não seria um órgão simbolizado, e para isso seria totalmente dependente da cultura. Desta forma, algumas das funções mais impressionantes do cérebro teriam origem puramente cultural; ou seja, mentes simbolizadas não são aparelhos neurais autossuficientes como é, por exemplo, o nosso sistema visual.

Depois de comentar sobre teóricos inatistas e culturalistas, Tomasello (1999), demonstrando compartilhar daquela compreensão, sugere que a sua própria posição é a de que processos culturais e sociais são partes integrantes e essenciais do caminho ontogenético normal de muitas das mais fundamentais e universais habilidades cognitivas, especialmente aquelas que são exclusivas da espécie humana. Afirma também que seres humanos são espécies típicas da teoria da herança dual, pois seu desenvolvimento depende inicialmente tanto da herança biológica quanto da cultural. Neste sentido, seríamos peixes em águas da cultura, embora o mundo cultural não estivesse livre do mundo biológico. Isto porque os processos culturais e sociais não criam habilidades cognitivas básicas durante a ontogenia, o que fazem é transformar habilidades cognitivas básicas em habilidades cognitivas complexas e sofisticadas (Tomasello, 1999). Tais processos agilizam, capacitam, mas não originam a capacidade de construir 
significados; põem-na em funcionamento quando seus componentes atuam conjuntamente. Há um progresso nestas habilidades cognitivas básicas que, acredita-se, é produto da construção de significados.

Maturana (2001) declara sua concordância com a "moeda de duas faces" quando lembra que a capacidade cognitiva de um indivíduo acaba a partir do momento em que seu cérebro morre, afirmando, dessa maneira, que não há como desconsiderar a biologia. A organização é, necessariamente, uma invariante (Piaget, 1979), como tudo que se processa é invariante, subentendendo uma estrutura, um sistema biológico; mas o resultado do processamento não o é. Em síntese, pode-se afirmar que Donald, Tomasello e Maturana concordariam com a participação do biológico no PCS, sem, entretanto, superestimar esta contribuição. Destarte, a ênfase da maioria dos estudiosos citados encontra-se, neste sentido, na face cultural.

Ao discutir o modelo de herança "dual", Tomasello utiliza ainda em seus argumentos questionamentos como: por que primatas são diferentes? Por que os humanos com déficits biológicos participam diferentemente de sua cultura? O levantamento destas questões representa uma tentativa de demonstrar que a conclusão de que seres humanos individuais possuem uma capacidade herdada biologicamente para viver culturalmente é inevitável. Esta capacidade, para este autor, é a de entender companheiros da espécie como agentes intencionais $^{4}$ como ele próprio. Entender outras pessoas como agentes intencionais possibilitaria (1) a criação colaborativa de práticas e artefatos culturais com história acumulada e (2) o processamento de aprendizagem e internalização de significados. Então, a questão que deve ser colocada neste momento é como esse processo de construção de significados é posto em movimento, como esta construção é internalizada e, posteriormente, ampliada. Investigações nesta direção possibilitariam mediações com contextos cujo cotidiano, como o educacional, se beneficiaria com estes conhecimentos, possibilitando intervações, que poderiam, inclusive, significar o resgate do prazer em aprender.

\section{CONSIDERAÇÕES FINAIS}

À pergunta "por que é relevante estudar o PCS?" pode-se responder que as análises a respeito têm

4 Agentes Intencionais são seres animados que têm objetivos e fazem escolhas ativas entre meios comportamentais para atingir tais objetivos, incluindo escolhas sobre ao que prestar atenção para alcançá-los. evidenciado a importância do tema tanto para a Psicologia, de maneira geral, como para a mente humana e sua constituição social, de maneira específica. Se considerarmos que a cognição diz respeito a todos os fenômenos vinculados à produção e ao processamento do conhecimento, então o fenômeno da significação, implícito nesses, diz respeito à Psicologia. Entre as principais teses da semântica cognitiva encontra-se a significação (meaning), estudada como parte da cognição humana, e não como estrutura linguística autônoma (Marcuschi, in press; p. 14-18). Alguns argumentos demonstram a fecundidade deste tema para a Psicologia, a despeito da sua complexidade e dificuldade de acesso. Os indivíduos, por exemplo, usam diferentes códigos e registros nos diversos contextos do discurso - fala de escola, fala de playground entre outros -, evidenciando a versatilidade do PCS.

Inúmeros estudiosos requisitam essa direção, a da construção de significados, para estudos em Psicologia Cognitiva. Walkerdine (1988) afirma que os aspectos psicológicos do engajamento de pessoas na produção de signos não têm sido diretamente discutidos pela Psicologia do desenvolvimento. Simon e Kaplan (1989) referendam esta idéia, lembrando que é na Psicologia Cognitiva que se estuda o pensamento humano, ou seja, os mecanismos pelos quais as pessoas agrupam (gather), processam, estocam e utilizam conhecimentos. Percy (1994), outro exemplo, reivindica o foco das investigações na construção de significados, ao mesmo tempo em que critica a direção clássica dos estudos em Psicologia, cujo foco tem sido em primeiro lugar o comportamento e depois o processamento de informações, mais do que a construção de significados (meaning-making). Reivindica ainda, como Bruner (1986 e 1997), o estudo do processo de construção de significados pela Psicologia, afirmando que deve haver um esforço para eleger o significado como conceito central desta ciência e uma busca por descobrir e descrever os significados que os indivíduos criam na interação com o mundo, assim como propostas específicas sobre o processo de construção de significado (meaningmaking).

Searle (2000) é mais um desses estudiosos que, pode-se dizer, vêm perseguindo as questões relacionadas ao processo de construção de significados, ilustrando suas próprias indagações com questões do tipo "como pode esse estado [por exemplo, a crença de que Clinton era presidente dos USA] do meu cérebro - que consiste em coisas como configurações de neurônios e conexões sinápticas, 
ativadas por neurotransmissores - 'significar' alguma coisa?" (p. 87) - questões que para este autor não poderiam ficar sem resposta.

De acordo com Vygotsky quando refletia sobre a gênese dos processos de pensamento e linguagem, discutindo os experimentos de Köhler com chimpanzés, o ponto central que nos diferencia dos outros animais, até daqueles mais semelhantes, seria o emprego funcional dos signos, ou seja, a nossa capacidade de construir significados, a mesma que tem sido pouco compreendida pela Psicologia. Ainda de acordo com esse autor e também com Bakhtin, discutidos em Freitas (1996), a relação da Psicologia com a construção de significados é muito clara, uma vez que o signo é um produto social cuja função é gerar e organizar processos psicológicos, realizando, assim, a mediação entre o indivíduo, os outros e ele mesmo e tornando-se a forma mais adequada para a investigação da consciência humana.

Não obstante, são poucos os estudos empíricos diretamente relacionadas a este processo, o que é paradoxal, uma vez que se trata de processos considerados essenciais para a cognição humana. Aparentemente, neste sentido, continuamos nos esquivando de determinados fenômenos, como se estivéssemos maquiando a superficialidade da Psicologia clássica que denunciamos há décadas. A chamada "revolução cognitiva" há mais de meio século protestou contra a superficialidade das investigações psicológicas e, essencialmente, contra a recusa em trabalhar processos ditos subjetivos entendidos como aqueles que não eram diretamente observáveis - e ainda contra a desvalorização de pesquisas que abordassem tais temas, o que leva a pensar que uma real transformação da Psicologia ainda não aconteceu.

As atuais análises e discussões sobre o PCS apresentam-se de forma essencialmente teórica, fato que não deve significar inacessibilidade empírica, pois, como afirma Maturana (2001), em princípio não existem restrições quanto ao tipo de fenômeno que pode ser abordado e explicado cientificamente. Enfim, observa-se que o incômodo com a falta de clareza em relação a alguns conceitos centrais para a Psicologia cognitiva é declarado por diferentes vozes. Tentar esclarecer a dinâmica deste processo deve ser uma tarefa principalmente da Psicologia, embora com suporte ou parceria de várias outras disciplinas cujo objeto se relaciona, da mesma maneira, com a importância da construção de significados para as funções psicológicas superiores, especificamente humanas.
Dessa forma, acredita-se que estudos nessa direção poderão trazer esclarecimentos e, assim, relevantes contribuições para a Psicologia Cognitiva e ciências que de alguma maneira dependem dos avanços desta para o seu próprio progresso. Nisto consistiu um dos objetivos deste ensaio: instigar reflexões sistemáticas sobre um tema que, como poucos na Psicologia, goza de consenso pelo menos em termos da sua importância - neste caso, para o funcionamento cognitivo: o processo de construção de significados.

\section{REFERÊNCIAS}

Bakhtin, M. (2002). Marxismo e filosofia da linguagem: problemas fundamentais do método sociológico da ciência da linguagem (10 edição). São Paulo: Hucitec.

Banks-Leite, L. (1995). Representação e comunicação: o estudo de funções lingüísticas em psicologia. $\underline{\mathrm{N}}$. 1, pp. 41-54. Temas em Psicologia (Cognição e Linguagem). Sociedade Brasileira de Psicologia. São Paulo.

Brait, B. (1997). (Org.). Bakhtin: Dialogismo e Construção de Sentido. Editora da UNICAMP: Campinas - SP.

Bronckart, J. (1999). Atividade de linguagem, textos e discursos: por um interacionismo sócio-discursivo. São Paulo: EDUC.

Bruner, J. (1986). Actual minds, possible worlds. Cambridge: Harvard University Press.

Bruner, J. (1997). Atos de significação. Porto Alegre: Artes Médicas.

Chauviré, C. (1991). Wittgenstein. Rio de Janeiro: Zahar.

Coll, C. e Edwards, D. (1998). Ensino, Aprendizagem e Discurso em Sala de Aula. Artmed: Porto Alegre.

Condé, Mauro L. L. (1998). Wittgenstein: linguagem e mundo. São Paulo: Annablume.

Correia, M. (2003). A constituição social da mente: (re)descobrindo Jerome Bruner e construção de significados. Estudos de Psicologia, 8 (3), 505-513.

Correia, M. F. B. \& Meira, L. R. L. (2008). Explorações acerca da construção de significados na brincadeira infantil. Psicologia: Reflexão e Crítica, 21 (3), 356-364.

Costa, C. (2003). Filosofia da linguagem. Rio de Janeiro: Zahar.

Donald, M. (2000). The central role of culture in cognitive evolution on the myth of the "isolated mind". In L. P. Nucci \& G. B. Saxe (2000). Culture, thought, and development. Mahwah, New Jersey, London: LEA.

Fauconnier, G. (1996). Introduction to methods and generalizations. In T. Janssen e G. Redeker (Ed.s). The Hague: Moution de Gruytes - Cognitive Linguistics Research Series.

Freitas, M. T. A. (2002). Vygotsky \& Bakhtin, psicologia e educação: um intertexto. São Paulo: EDUFJF/Ática.

Freitas, M. T. A. (1998). Vygotsky: um século depois. Juiz de Fora: EDUFJF.

Freitas, M. T. A. (1996). Vygotsky \& Bakhtin - Psicologia $e$ Educação: um intertexto. São Paulo: Ática 
Góes, M. C. R. (1995). A construção de conhecimentos: examinando o papel do outro nos processos de significação. Temas em Psicologia, 1, 23-30.

Goodwin, C. (2000). Action and embodiment within situated human interaction. Journal of Pragmatics, 32, 1489-1522.

Marcuschi, L. A. (in press). A construção do mobiliário do mundo e da mente: Linguagem, categorização e verdade. Aula inaugural do cursos de PG em Filosofia. UFPE. Recife. 17/05/2004.

Marková, I. (1990). A three-step process as a unit of analysis in dialogue. In Marková I., \& K. Foppa. (Ed.s). The Dynamics of Dialogue. Springer-Verlag: New York.

Maturana, H. (2001). Cognição, Ciência e Vida Cotidiana. Belo Horizonte: Ed. UFMG.

Meira, L., \& Lerman, S. (2001). The zone of proximal Development as a symbolic space. Social Science Research Papers, 1 (13), 140.

Morato, E. M. (1996). Linguagem e Coginição: As reflexões de L. S. Vygotsky sobre a Ação Reguladora da Linguagem. Plexus Editora: São Paulo.

Oliveira, M. K. (1995). Linguagem e Cognição: questões sobre a natureza da construção do conhecimento. Temas em Psicologia, $1,1-10$.

Percy, W. (1994). Homo symbolificus. In R. T. Kellogg (org.), The psychology of writing. New York: Oxford University Press.

Piaget, J. (1990). A formação do símbolo na criança. $3^{\mathrm{a}}$ edição.Editora Afiliada, LTC: Rio de Janeiro.

Piaget, J. (1979). A construção do real na criança (3ª edição). Rio de Janeiro: Editora Zahar.
Pino, A. (1995). Semiótica e cognição na perspectiva históricocultural. Temas em Psicologia, 1, 31-40.

Searle, J. R. (2000). Mente, Linguagem e Sociedade: Filosofia do Mundo Real. Rio de Janeiro: Rocco.

Simon, H., \& Kaplan, C. (1989). Fondations of cognitive science. In Posner, M. (Ed.). Foudation of Cognitive Science. Cambbridge /Massachusetts. A Bradford Book. pp. 1-46.

Smolka, A. L. B. (1995). A concepção de linguagem como instrumento: um questionamento sobre práticas discursivas e educação formal. Temas em Psicologia, 1, 11-22.

Tomasello, M. (1999). The cultural origins of human cognition. Cambridge: Harvard University Press.

Valsiner, J. (2002). Irreversibility of time and Ontopotentiality of signs. Estudios de Psicologia.

Valsiner, J. (2001). Affective fields and their development. In J. Valsiner (ed.), Comparative study of human cultural development (pp.159-181). Madrid: Fundación Infancia y Aprendizaje.

Vygotsky, L. S. (2001). A construção do pensamento e da linguagem. São Paulo: Martins Fontes.

Vygotsky, L. S. (1991). A Formação Social da Mente. São Paulo: Ed. Cortez.

Walkerdine, V. (1988). The Mastery of Reason: Cognitive Development and the Production of Racionality. Routledge: London.

Recebido em 22/08/2007 Aceito em 06/10/2008
Endereço para correspondência :

Mônica F. B. Correia, Rua Geraldo Mariz, 525/501. Tambauzinho, CEP 58.042-060, João Pessoa-PB, Brasil.E-mail: moncorreia@uol.com.br 